\section{Bedside Containers}

\section{To the Editor:}

I am calling on your expertise to resolve a problem existing in a few long-term care facilities in the Los Angeles area: some directors of nursing and administrators (very few) have resisted sanitizing bedside water containers on a daily basis. Their schedule ranges from three times weekly to weekly. I have not been able to determine a schedule from CDC guidelines but concur with most directors of nursing, administrators, and infection control committees of skilled nursing facilities that the minimum acceptable sanitizing is once daily.

Infection Control is the bible in all skilled nursing facilities with which I am associated as medical director or utilization review chairman.

Harry J. Silver, MD Los Angeles, California
Ms. Sue Crow, nurse epidemiologist, responds to Dr. Silver's letter:

When making decisions related to infection control, consider whether or not the procedure will affect a sterile area of the body. If so, strict sterile technique is necessary. If the procedure involves an area such as the GI tract, clean technique only is necessary. Regarding water pitchers, there are no studies implicating these items as a source of nosocomial infection. Because the contents will enter the GI tract, I am not so sure it is important to clean the water pitchers daily. Obviously, if the pitchers are dirty, they need cleaning. I have no problem suggesting cleaning them three times weekly or even weekly. More important is that patients receive the same water pitcher after cleaning. I continue to note this problem in hospitals and nursing homes and suggest labeling water pitchers so this mismatch will not occur. Reusable water pitchers should receive, at minimum, highlevel disinfection before being used by other patients.

At our hospital we clean water pitchers either when they become soiled or on a weekly basis, with no apparent risk.

Sue Crow, MSN, RN, CIC Nurse Epidemiologist Louisiana State University Medical Center Shreveport, Louisians

Letters to the Editor should be addressed to INFECTION CONTROL Editorial Offices C4I General Hospital, University of Iowa Hospitals and Clinics, Iowa City, IA 52242. All letters must be typed, double spaced, and may not exceed four pages nor include more than one figure or table. The editors reserve the right to edit for purposes of clarity or brevity. 